Article

\title{
Proposal for Planning an Integrated Management of Hazardous Waste: Chemical Park, Jiangsu Province, China
}

\author{
Weixia Wang ${ }^{1,2}$, Jian Bao ${ }^{1,2, *}$, Sijia Yuan ${ }^{1,2, *}$, Haiyun Zhou ${ }^{2}$ and Guoping $\mathrm{Li}^{2}$ \\ 1 Jiangsu Provincial Key Laboratory of Environmental Engineering, Nanjing 210036, China; \\ wxwang08@163.com \\ 2 Jiangsu Provincial Academy of Environmental Science, Nanjing 210036, China; joisen@163.com (H.Z.); \\ Ligp@jshb.gov.cn (G.L.) \\ * Correspondence: baoj@jshb.gov.cn (J.B.); yuansj.nju@gmail.com (S.Y.)
}

Received: 1 March 2019; Accepted: 15 May 2019; Published: 19 May 2019

\begin{abstract}
This study elucidates the current state of hazardous waste management in industrial parks with a particular focus on Jiangsu Province. The development of the Internet of Things and big data technology has encouraged the application of intelligent technologies for hazardous waste management. However, the concept of considering each chemical park as a large enterprise have been suggested to reduce potential risks from the transportation of hazardous waste, help local environmental protection departments intuitively understand the position of park administrators, and to realize cyclic utilization of hazardous waste resources. We propose integrated management of hazardous waste at the chemical park level. In this study, principles such as integrated closed management, data unification, clustering management, and intelligent technologies were introduced for hazardous waste management in chemical parks. Additionally, potential approaches, such as a unified environmental butler service, an intelligent standard box system, and system optimization scenarios, are proposed and comprehensively explained. These approaches are likely to enable informed, structured, comprehensive, and interdisciplinary management of hazardous waste not only in chemical parks but also in industrial parks in general in the future.
\end{abstract}

Keywords: hazardous waste management; chemical parks; cyclic utilization; large-scale enterprise; intelligent technology; Jiangsu Province

\section{Introduction}

Hazardous waste (HW) is defined as "solid waste that is listed in the national list of hazardous waste or identified to be dangerous according to the identification criteria and methods of hazardous waste as prescribed by the State" in China [1]. The quantity of waste generated owing to recent industrialization in China is rapidly increasing, and the management of HW production is exigent [2]. Hazardous materials contain explosive, flammables, oxidizing substances, poisonous gases, and radioactive materials [3]. Therefore, ineffective hazardous waste management (HWM) is detrimental to the environment and human health due to exposure of these toxic ingredients. A review by Fazzo et al. lists several investigations, that indicate poor and illegal waste management as the most important world-wide cause of soil and groundwater contamination [4]. Source reduction and efficient HWM are essential to address the potential hazards of HW (particularly those resulting from improperly identified, treated, recycled, stored, transported, and disposed HW) to human health and the environment [5]. Hence, certain measures have been undertaken to improve HWM at both national and local levels in China. Table 1 lists laws, regulations, judicial interpretation and department rules relating to HWM which have been revised or released during the past five years. 
Table 1. Laws and regulations of the past five years in the field of hazardous waste management (HWM).

\begin{tabular}{|c|c|c|}
\hline Types & Name of the Documents & Revision/Release Time \\
\hline Laws & $\begin{array}{l}\text { Law of the People's Republic of China on the } \\
\text { Prevention and Control of Environment } \\
\text { Pollution Caused by Solid Wastes (2016 } \\
\text { Revision) }\end{array}$ & Revised in 2016 \\
\hline Regulations & $\begin{array}{c}\text { Jiangsu Province Solid Waste Pollution } \\
\text { Environment Prevention and Control } \\
\text { Regulations }\end{array}$ & Revised in 2017 \\
\hline Judicial Interpretation & $\begin{array}{l}\text { Interpretation of the Supreme People's Court } \\
\text { and the Supreme People's Procuratorate on } \\
\text { Several Issues concerning the Application of } \\
\text { Law in the Handling of Criminal Cases of } \\
\text { Environmental Pollution (2016) }\end{array}$ & Released in 2016 \\
\hline Departmental Rules & $\begin{array}{l}\text { Directory of National Hazardous Wastes } \\
\text { (2016 Revision) } \\
\text { Identification standards for solid wastes } \\
\text { general rules } \\
\text { General specifications of engineering and } \\
\text { technology for hazardous waste disposal } \\
\text { Technical specification for coprocessing of } \\
\text { solid waste in cement kiln } \\
\text { Guidelines for environmental impact } \\
\text { assessment of hazardous wastes in } \\
\text { construction projects }\end{array}$ & Released in 2014 \\
\hline
\end{tabular}

The "Directory of National Hazardous Wastes" was revised in 2016 to adjust the number of HW species from 400 in 49 original categories to 479 across 46 categories [6]. The publication and implementation of the new edition have resulted in comprehensive and scientific management of HW. Furthermore, the Ministry of Ecology and Environment (formerly the Ministry of Environmental Protection) has been promoting the "Solid Waste Management Information System" (with HWM as its core) for several years to further improve and implement scientific and networked management of solid waste. Some regions in China have established (or are in the process of establishing) HW-based supervision platforms. Additionally, a few places (e.g., Hangzhou in the Zhejiang Province), have introduced intelligent logistics labels (such as two-dimensional codes) and global positioning system (GPS) based terminal radio frequency identification (RFID) technology, among other methods, to reduce environmental risks associated with transfer and disposal of HW (here, disposal refers to incineration, landfilling, and related ultimate treatment activities). However, most such processes are still in the nascent stage and much room for improvement exists.

Industrial parks, which are the most common method of allocating industrial entities, generate high quantities of HWs. They are prospered as centers of regional economic development in China and significant challenges in industrial solid waste management exist owing to the large quantities of wastes generated [7]. Documents issued by the Office of the Work Safety Commission of Ministry of Emergency Management of the People's Republic of China claimed that "New chemical construction projects must enter industrial concentration zones or chemical industrial parks, and gradually promote existing chemical enterprises to enter the zones and parks" [8]. The intensive development in industrial parks has advantages and drawbacks in contrast to the traditional decentralized development model. For instance, on the one hand, chemical industries in a chemical park help reduce production costs by comprehensive utilization of chemical materials and energy flow, which is beneficial for centralized treatment and efficient utilization of waste.

On the other hand, the relatively high concentration of enterprises in a chemical park as well as the presence of numerous hazardous chemicals and complex chemical processes, large scale equipment, and several significantly hazardous sources result in higher potential risks for the environment and local residents. Thus, implementation of safe and environmentally friendly HW management is critical for sustainable development of chemical parks. However, studies on integrated HWM at the 
industrial park level are limited because most published research has primarily focused on general waste management in industrial parks.

Previously, research on chemical parks in Jiangsu Province with emphasis on HWM has been conducted by the authors [9]. The results indicated that chemical parks generate large amounts and complex varieties of HWs. The typical challenges for entities (especially small and middle-scale entities that do not generate much HW) discharging HW are improper disposal and over-time storage of HW. Entities with disposal facilities are usually unwilling to accept HW from small or middle-scale entities owing to the high cost of partially loaded transportation. Additionally, inadequate attention has been paid to the regulation of HW storage, which increases environmental risks and pressures with regard to environmental supervision. Therefore, several integrated management plans have been developed in response to the abovementioned problems from relevant documents, including the "Jiangsu Province Ecological Environmental Protection System Comprehensive Reform Plan", for better HWM in chemical parks. The main objectives of such plans are to treat each chemical park as a large-scale enterprise and integrate supervision of HW storage, utilization, and disposal within the park.

This study aims to focus on the innovative management models of "point-to-point recycling" and "centralized collection and storage" and introduces the idea of integrated management to achieve more effective HWM in chemical parks. The definition of "integrated waste management" proposed by the United Nations Environmental Program (UNEP) in 1996 (i.e., "a framework of reference for designing and implementing new waste management systems and for analyzing and optimizing existing systems" [10]) was considered as the reference in this study.

\section{Current State of HWM at Chemical Parks in Jiangsu Province}

In 2016, 202 large and medium-scale industrial parks in China generated 40.10 billion tons of HW; Shandong, Jiangsu, and Hunan were the top three provinces with regard to the volume generated [11].

Chemical parks have been the focus of environmental protection supervision at the provincial level owing to the complex composition and toxicity of large quantities of HW generated each year.

Figure 1 and Table 2 show the location of 53 chemical parks in Jiangsu Province. The list of chemical parks is taken from Jiangsu Municipal People's Government Notice [12].

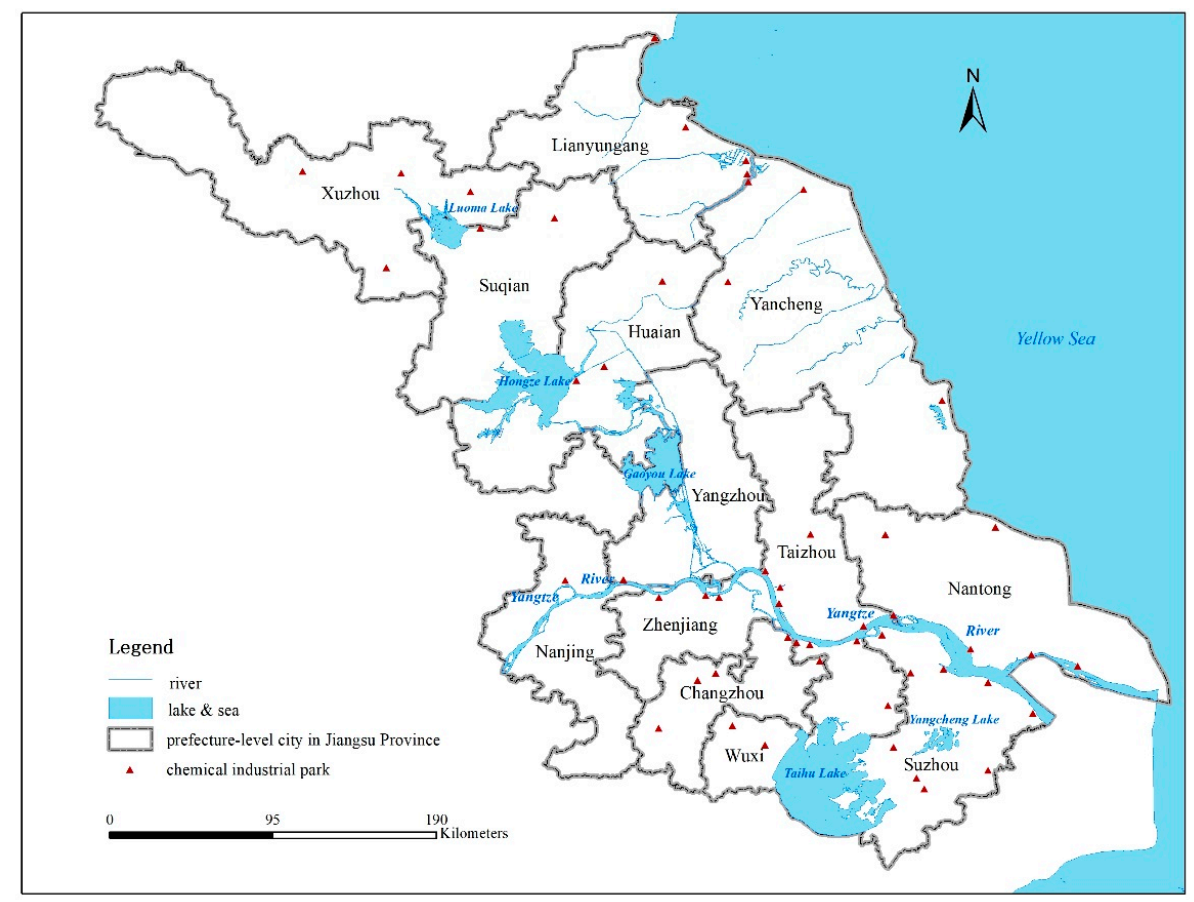

Figure 1. Fifty-three chemical parks' location in Jiangsu Province. 
Table 2. Number of chemical parks in each city in Jiangsu Province.

\begin{tabular}{cccc}
\hline Region & Location & Number of Chemical Parks \\
\hline \multirow{4}{*}{ South-Jiangsu } & Nanjing & 1 & \\
& Suzhou & 9 & 24 \\
& Wuxi & 6 & \\
& Changzhou & 5 & 12 \\
& Zhenjiang & 3 & \\
Central-Jiangsu & Yangzhou & 1 & 17 \\
& Nantong & 6 & \\
& Taizhou & 5 & \\
North-Jiangsu & Xuzhou & 4 & \\
& Lianyungang & 4 & \\
& Suqian & 2 & \\
& Yancheng & 4 & \\
& Huaian & 3 & \\
\hline
\end{tabular}

Although environmental remediation standards for HWM have improved in recent years, the phenomenon of untimely and inefficient treatment and disposal of certain types of HW still exists. Apart from this, HWM not being in compliance with national and local standardized management rules is another problem. Table 3 below lists some typical issues of HWM at the chemical parks level according to authors' research in 2016 and 2017.

Table 3. Typical issues of HWM in a chemical park in Jiangsu Province.

\begin{tabular}{ll}
\hline Typical Issues of HWM in a Chemical Park in Jiangsu Province \\
\hline At the Management Level & $\begin{array}{l}\text { Enterprises fail to effectively implement the whereabouts of HW } \\
\text { and overdue storage phenomenon is serious. }\end{array}$ \\
Ledgers from some enterprises are inconsistent with the actual \\
disposal amount and whereabouts of some types of HW, such as \\
distillation residue and waste sludge kept unknown. \\
The design of the HW storage places are not implemented \\
according to the requirements of the Environmental Impact \\
Assessment and labels of hazardous waste packaging are missed or \\
have not been marked.
\end{tabular}

- Waste salt:

At the Treatment and Disposal Level, Taking Several Types of Hazardous Waste for Example.
About $990 \mathrm{t}$ waste salt was produced in 2015 inside this chemical park. Due to the lagging construction of the planned incineration facility inside the chemical park, most of the waste salt can only be stored inside the enterprise beyond the time limit.

The quality of waste salt by-products produced by some enterprises cannot meet the requirements of raw salt, and it is difficult to determine the whereabouts of by-product salt.

- Waste activated carbon:

About $550 \mathrm{t}$ waste activated carbon was produced in 2015 inside this chemical park and most of it is outsourced for disposal by incineration. Some enterprises temporarily store the waste activated carbon in the factory due to high disposal price, leaving environmental risks inside the chemical park.

- Waste acid:

About 1450 t (concentration: 20\%-75\%) was produced in 2015 inside this chemical park. The large variety of waste acid types make it difficult to realize waste acid recycling.

- $\quad$ Sludge:

The annual sludge output of one enterprise inside this chemical park is $2304 \mathrm{t}$ in 2015 and the temporary storage amount in 2016 reached $9477 \mathrm{t}$, causing considerable environmental risk. 


\subsection{Current HWM Approaches in Chemical Parks in Jiangsu Province}

\subsubsection{Innovation Action of Centralized Storage and Collection}

The innovation action of centralized storage and collection has been suggested to assist small and medium-sized enterprises (SMEs) to manage HW better. In this study, no specific definition was adopted for SMEs and it depended on the management team of each region or chemical park. In general, SMEs are entities that produce HWs in small quantities or types that are difficult to dispose of, and entities that are located in a decentralized manner in the park. The main objective of centralized collection, classification, and storage is to reduce both environmental regulatory pressures and environmental risks. In addition, this approach addresses the challenges in HW collection, storage, and management by SMEs in a unified manner.

Presently, a few regions across the nation have conducted the pilot work for centralized collection of HW at the industrial park level. The Shanghai Environmental Protection Bureau released the "Shanghai industrial park hazardous waste collection and storage and transit facilities management measures (trial)" document in December 2016. In May 2017, the Ministry of Environmental Protection of Jiangsu Province issued a notice on "the issuance of a pilot program on the centralized collection and storage of hazardous wastes in Jiangsu industrial park." To date, a company located in the Suzhou industrial park has initiated centralized collection, storage, and transfer of HWs in SMEs that generate less than 10 tons of HW per year. The project-related equipment and facilities have been installed. Additionally, the control measures have been implemented and are currently in the commissioning stage.

In the previous research, a feasibility study report on a new centralized collection and storage project for HW has been put forward [9]. In this report, ten main parts has been elaborated in detail (Table 4).

Table 4. Main parts of a feasibility study report on a new centralized collection and storage project for hazardous waste (HW).

\begin{tabular}{cc}
\hline Part 1 & Site selection and construction conditions \\
\hline Part 2 & Engineering design for centralized storage of hazardous waste \\
\hline Part 3 & Utilities and supporting implementation programs \\
\hline Part 4 & Fire protection design \\
\hline Part 5 & The environmental protection \\
\hline Part 6 & The risk assessment \\
\hline Part 7 & Organization and implementation of engineering projects and allocation of \\
\hline Part 8 & Project implementation plan \\
\hline Part 9 & Project investment estimation \\
\hline Part 10 &
\end{tabular}

Due to the reality of the chosen chemical park, the centralized collection and storage project for hazardous waste has not been implemented in that chemical park. However, some concepts and principles raised in the feasibility study report do have instructive significance. Four steps of centralized collection and storage of HWs in chemical parks (Figure 2) have been introduced.

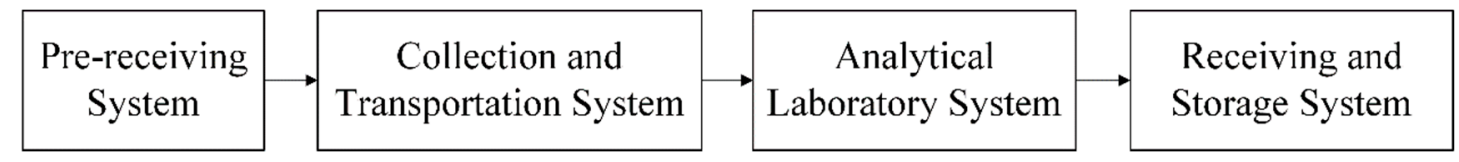

Figure 2. Steps for centralized collection and storage of hazardous waste (HW). 
The first step is the pre-receiving system before the formal reception of HW. Necessary information for the HW to be received should be obtained during pre-receiving to prevent environmental risks. Thus, guidance in this regard focuses on HW classification, standardized packaging, and other measures before initiating the centralized storage process. The second step is the collection and transportation system, which focuses on important factors such as the operation license for HW transport, HW transport drivers, escort certificates, and development and training for emergency plans during HW transport. In this system, risk control is supported by installation of the GPS, fire extinguishers, and sand as well as absorbent cotton and other leakage collection items. The third step is the analytical laboratory system. Through experimental analysis, a reasonable storage scheme, including both pre-factory and post-factory analyses, is formulated. Pre-factory analysis includes factors such as price determination, packaging, and treatment methods whereas post-factory analysis aims to provide the basis for storage and treatment. Risk control is an important factor here and fingerprint analysis, and trial-batch experiments are conducted to ensure that HW storage meets national emission standards and environmental accidents caused by pollution are prevented. The fourth step is the receiving and storage system. Each barrel is labeled before storage of the waste. Additionally, classification of HW according to hazard type and zoning storage is executed. Furthermore, installation of leakage collection systems, and emergency facilities in the warehouse are necessary for risk control.

\subsubsection{Dynamic Management Systems for HW}

To strengthen the monitoring and management of HW, Jiangsu Province has developed a dynamic HW management system (Hazardous Waste Dynamic Management System of Jiangsu Province, HWDMSJP) based on big data and the Internet of Things (IoT) technology. Main modules are listed as shown in Figure 3, though access authority of each module differs from entities and the local environmental protection administrative department. The system uses a data-driven approach to install the IoT real-time monitoring equipment in HW vehicles and collect data on waste information, geographic location as well as images and video data over a period of $24 \mathrm{~h}$. These data are subsequently sent to the data center over a wireless network for further storage and processing.

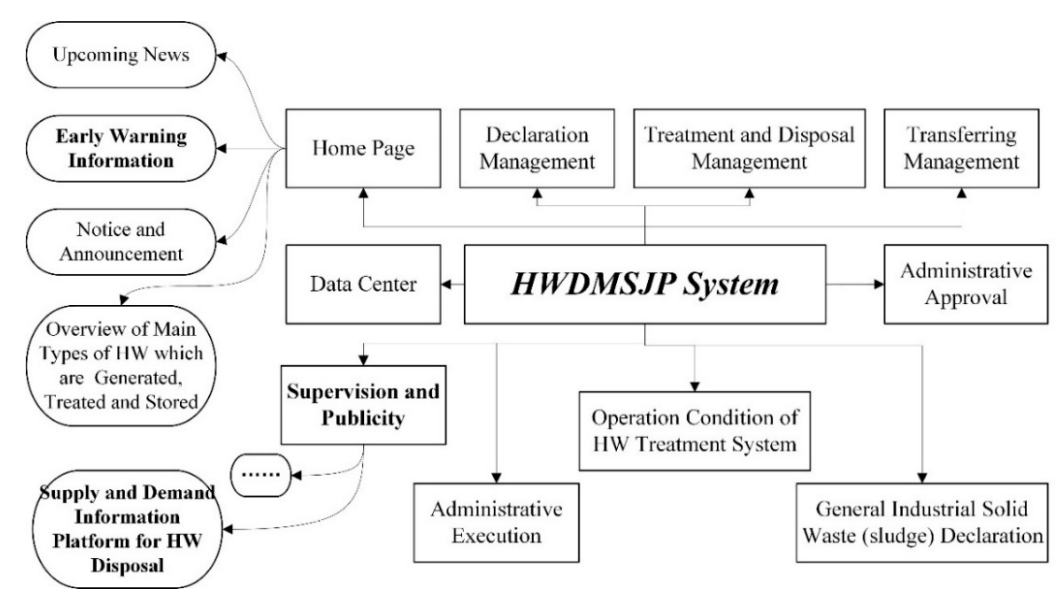

Figure 3. Functional map of the Hazardous Waste Dynamic Management System of Jiangsu Province, (HWDMSJP). HW, hazardous waste.

In this system, entities that discharge HW are required to provide yearly HW management plans with detailed information on predicted HW types, quantities, storage, and transfer plans. Actual HW generation and management information need to be reported online in a timely manner, usually at the end of each month. Electronic duplicates for the transferred HW should be used during the HW transfer process for real-time feedback to transfer data. Additionally, GIS (Geographic Information System) map functions and spatial analysis technology allow real-time tracking of vehicle trajectory to further strengthen safety regulations during HW transportation. Moreover, the entity log book 
should be carefully monitored during HW treatment. A more comprehensive and reliable basis for supervision and management can be established through surveillance videos, 3D simulation models, and visual supervision of treatment facilities.

Furthermore, the following measures should be considered with regard to governments and local environmental protection departments. First, paperless office transactions, such as electronic approval process and remote supervision of law enforcement, can significantly save time and improve working efficiency. Second, HW supervision requires in-depth excavation analysis of data through big data technology to achieve cross-service data sharing. Subsequently, relevant information, such as the HW $\log$ book of each entity in electronic form and timely statistical reports classified by region or HW type, is provided to governments and local environmental protection departments, which significantly enhances the scientific management of HW.

\subsection{Problems to Be Addressed}

Although Jiangsu Province has undertaken several initiatives with regard to HW management, there remains room for improvement. Firstly, so-called "from cradle to grave" supervision mainly focuses on the transfer and treatment of HW. However, attention to HW generation and storage is lacking. Although entities are required to provide the yearly plan and declare the state of HW every month, HW management could be deregulated if an entity does not declare information during the generation phase.

Secondly, SMEs in industrial parks generate large quantities of HW, which further contributes to challenges in HWM at chemical parks. Geng et al. reported that SMEs constituted over $90 \%$ of total companies in the studied chemical parks and several did not practice efficient HWM [13]. Ozaki et al. concluded that the bulk of HW from small-scale factories is reportedly dumped into waterways and land-disposal sites without any pre-treatment [14]. Additionally, such enterprises usually lack staff specialized in solid waste management.

Thirdly, HW storage areas in several companies are still not sufficiently regulated. Paper-form labels are sometimes fragile and tend to fall off or break during waste transport. Although marking generation data and other detailed information on the label is required, often entities do not obey this rule. Thus, it is often challenging to trace a specific bucket or sack of HW.

\section{Methodologies for Integrated HW Management}

In this section, the main principles and possible approaches for HW management are suggested based on previous studies to provide solutions for unaddressed HW management problems in Jiangsu Province (Figure 4).

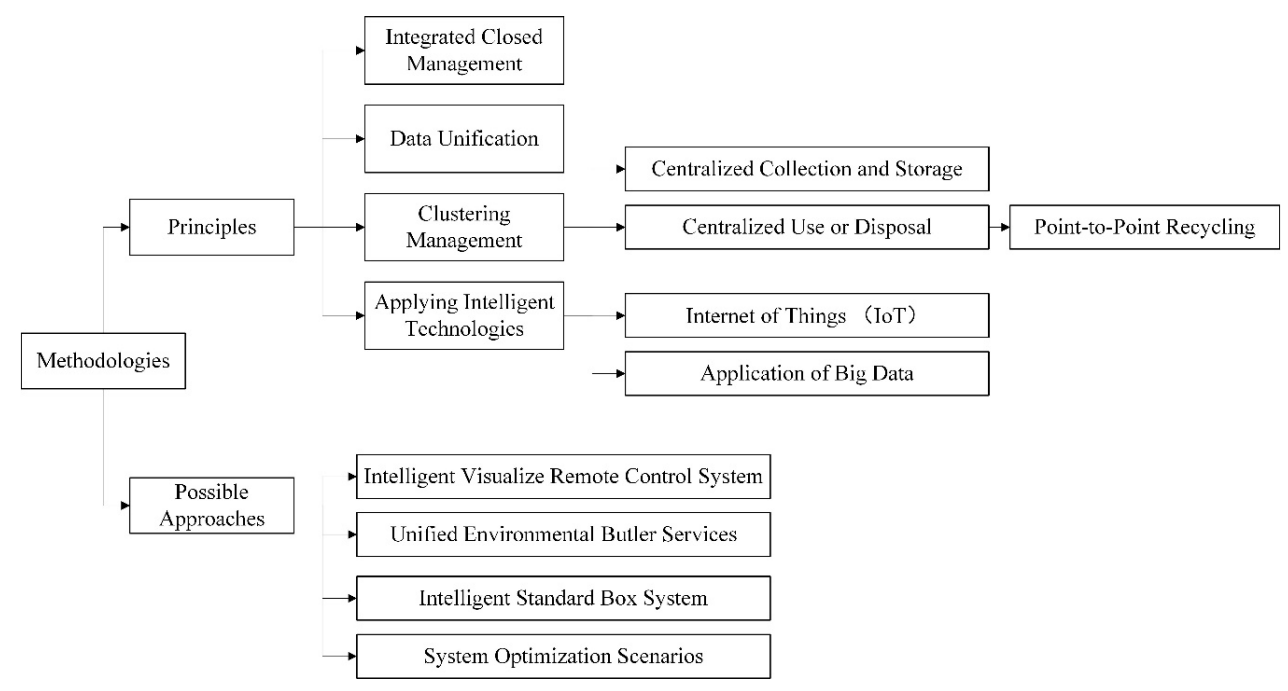

Figure 4. Roadmap of methodologies for integrated hazardous waste (HW) management planning. 


\subsection{Principles}

Several principles for achieving high-efficiency HW management in industrial parks are indicated as follows.

\subsubsection{Integrated Closed Management}

The Ministry of Industry and Information Technology of the People's Republic of China (MIIT) issued a document in 2015 to encourage large parks or parks close to surrounding residential areas to implement closed management [15]. For those parks that temporarily cannot conduct closed management, major hazard sources and key production areas inside the park are suggested for closed management.

The advantages of integrated closed management are that each chemical industrial park can be regarded as a large enterprise, and the resources for storage, utilization and disposal of HW within the park can be integrated for unified supervision. Owing to the dependence of the industrial chain and industrial clustering on building a recycling industry, the production of HW in the park is reduced at the source, and classified management is conducted to reduce the risks in the production process. Furthermore, it is conducive to the supervision and management of the management department.

\subsubsection{Data Unification}

The cradle-to-grave process of HWM includes source reduction, storage management, transportation, and disposal of waste. Each part involves different entities. Additionally, information and data are transmitted from and recorded in different platforms such as the enterprise resource planning system of the HW producer (if available), the HWDMSJP hosted by the local environmental protection administrative department, and, occasionally, the road transport system. Data unification includes merging and sharing of data from multiple sources to aid efficient supervision and risk reduction during HW management.

In China, it is necessary to fill duplicate forms for transfer of HW. Many provinces, including Jiangsu, utilize electronic forms in this regard. Additionally, duplicate electronic forms are required by a few local transportation bureaus during road transport of dangerous goods. In Jiangsu, two types of duplicate electronic forms that are run synchronously are required. Moreover, only transportation companies that are registered with the transportation department are permitted to transfer HW.

As indicated previously, one of the principles of HWM in industrial parks is to regard it as a large enterprise. Some industrial parks have already provided information in this regard on pollution prevention and control platforms such as wastewater pollution control, air pollution control, smart energy management, and smart security management. However, such information platforms do not exist for individual industrial parks, which focus on managing HW internally. In this study, an individual HW information platform is suggested at the industrial park level. The HW information platform for each industrial park would run independently; however, the core data will be synchronized and stored in the HWDMSJP. Centralized control and integration of all data could be enforced through the seamless connection between individual HW information platforms and the HWDMSJP.

\subsubsection{Clustering Management}

In this study, clustering indicates two main aspects: centralized collection and storage for SMEs and cyclic utilization of HW inside the industrial park. The aim is to capitalize on scale disposal to reduce both labor and resource costs.

- Centralized collection and storage for SMEs

Centralized collection and storage mainly serve the SMEs. Although the amount of HW generated by these companies is small, the waste type significantly differs. Additionally, HW treatment entities often charge high transportation and disposal fees, which waste-generating entities are unable to afford. 
Therefore, the SMEs are unable to establish an effective disposal method, and thus allow waste to be stored at the warehouse for long durations, further resulting in increased environmental risks and release of odor from wastes such as sludge. The implementation of centralized collection and storage for SMEs that generate a similar type of HW and collective transport to the treatment facilities could mitigate these challenges.

- Cyclic utilization of HW inside chemical parks

HWs often contain one or more useful substances, making them a potentially recyclable resource for downstream enterprises. However, the study and practice of cyclic utilization of HW at the industrial park level are limited. In this study, possible methods for cyclic utilization of HW have been suggested based on the authors' previous study [9] on technical methods for "point-to-point utilization of waste acid" in a chemical park in Jiangsu Province.

Ideally, all HW generated should be digested inside the park. In particular, HW can be used as raw material for other entities after some pre-treatment. Entities equipped with treatment facilities should accept HW from other entities if capacity for treatment of additional HW exists.

Large-scale enterprises with HW disposal facilities are encouraged to accept certain types of HW from other companies inside the industrial park if a capacity margin exists. Additionally, enterprises that produce the same type of HW could collaborate to build and utilize disposal facilities to reduce disposal costs. Furthermore, point-to-point recycling is an efficient way to reduce HW. For example, waste acid generated from one company, if properly handled, could be utilized as raw material for another company (Figure 5).

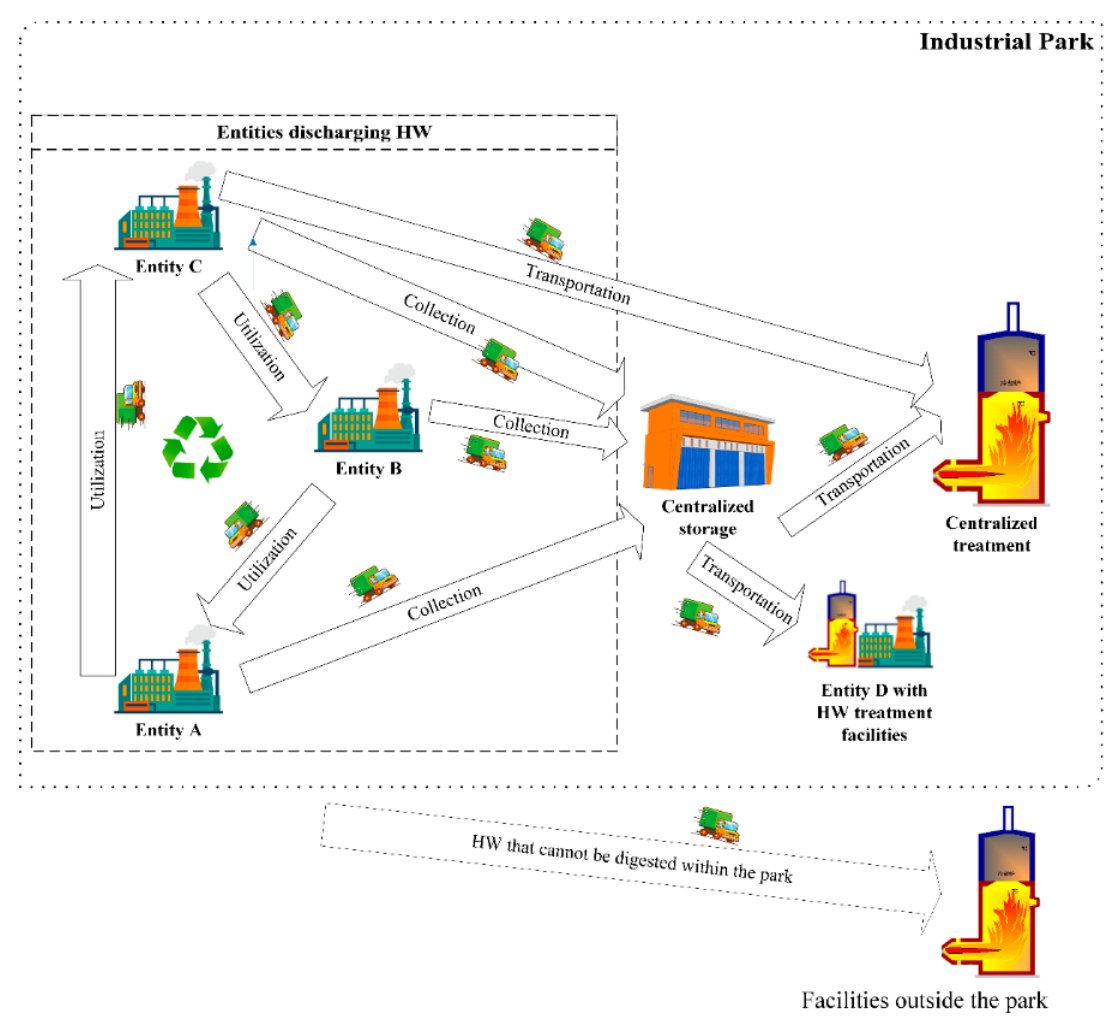

Figure 5. Possible pathways for cyclic utilization of hazardous waste management (HWM) in an industrial park.

\subsubsection{Application of Intelligent Technologies}

In 2015, the State Council of China issued a declaration promoting "Internet Plus" guidelines for utilizing the IoT and big data analysis technology to optimize information collection, data analysis, and waste flow tracking [16]. Application of IoT and big data as representative new technologies can 
promote effective utilization of solid waste and improve prevention and control of environmental risks. IoT is a massive network of numerous information-sensing devices that capture, in real time, any object or process that needs to be monitored, connected, and interacted with and gather information about its sound, electricity, light, location, and other characteristics. Therefore, IoT technology can be utilized for transforming everything into data that can be subsequently monitored to better implement regulations and improve regulatory efficiency. Wang et al. concluded that the environmental Internet of Things (EIoT) has several potential applications in environmental monitoring, simulation, and management [17]. A nationwide EIoT can promote environmental digitization in China and improve the scientific management of urban environments. Moreover, big data analytics have been used to develop industrial symbiosis in large cities. Bin et al. proposed a big data analytics approach to realize industrial symbioses. Three major elements were included in the solution framework; that is, data discovery and repository building to develop a big database, eco-network detection, and eco-network evaluation and optimization [18].

\subsection{Potential Approaches}

\subsubsection{Unified Environmental Butler (EB) Service}

A document issued by the Ministry of Environmental Protection in April 2016 introduced the concept of the "environmental butler" (EB) service. The EB represents a third-party environment-related service provider. In general, EBs provide environmental monitoring and pollution control services to companies. This initiatively aims to promote the development of the environmental advisory services industry to encourage qualified industrial parks to employ third-party professional environmental protection service companies as "environmental housekeepers" to provide integrated environmental services and solutions.

Tian et al. reported that the primary purpose of introducing the EB to the park and its entities is to demonstrate efficient HW management [19].

At the level of park entities, the EB service mainly focuses on SMEs that discharge HW. The EB service assists several aspects of HW management such as identification of HW, introduction of technology for source reduction of HW, standardized management of HW storage and transportation, and training of staff.

At the level of the chemical park management committee, the EB primarily focuses on the following. Firstly, assisting the park management committee in supervision of daily operations at environmental protection management facilities of enterprises. Secondly, regularly conducting a full range of environmental risk checks to perform environmental and pollution source testing for enterprises in the park, suggesting rectification plans for identified problems, and guiding their implementation. Thirdly, promptly following up and interpreting recent laws, policies, and standards issued by the State to suggest corresponding improvement measures considering the actual situation of the park in order to achieve sustainable development.

\subsubsection{Intelligent Standard Box System (ISBS)}

Lu et al. applied intelligent technologies to waste management and designed a real-time information monitoring management platform for utilization during storage and transportation of waste; these systems comprise RFID, GPS, and GIS technologies to provide an objective and accurate basis for pollution control and environmental policy enforcement [20]. A GIS-based optimal routing model was developed based on parameters such as population density, waste generation capacity, road network, and types of road, storage bin, and collection vehicle to trace minimum cost/distance efficient collection paths for transporting solid wastes to landfills [21]. Hannan et al. presented a review of solid waste management and reported that the weight of waste is measured at the disposal site; however, little is known about measurements at source sites [22]. A smart bin can address this problem by acquiring daily data for physical variables such as bin fill level, weight, volume, and 
ambient conditions for each bin. Therefore, data acquisition technologies are required in this regard. This approach can be extended to HW management.

In this study, the authors propose the ISBS as an effective measure for efficient realization of centralized collection and storage. This scheme can be applied to all entities inside the chemical park for unified management. As an important part of holistic HW management, this scheme focuses on standardized management of all types of HW generated in the park during different stages (i.e., generation, storage, transfer, and disposal). Table 5 presents the basic elements of the ISBS (i.e., the standard box facility, smart scale, server, and application programs).

Table 5. Elements of the intelligent standard box system.

\begin{tabular}{cl}
\hline \multicolumn{1}{c}{ Element } & \multicolumn{1}{c}{ Description } \\
\hline Standard Box Facility & $\begin{array}{l}\text { Basic modules include container and intelligent identification } \\
\text { modules (passive radio frequency identification [RFID]). } \\
\text { Optional modules include intelligent logistics lock (w/o global } \\
\text { positioning system [GPS]) and GPS equipment }\end{array}$ \\
\hline Intelligent scale components are weighing parts, 4G communication \\
components, and RFID components \\
Smart scale weighs and uploaded weight information; uploaded \\
data are bound to the server
\end{tabular}

A

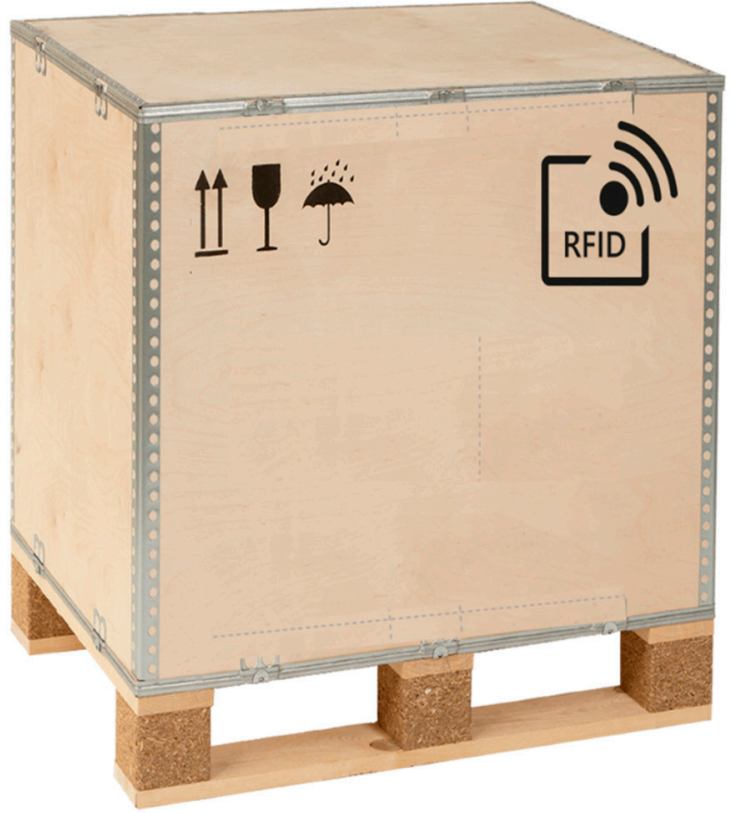

\section{B}

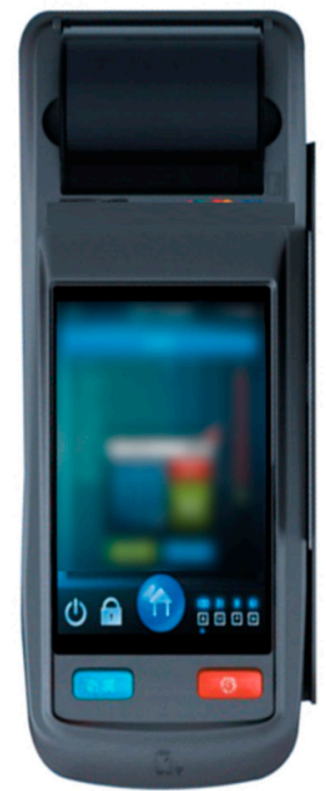

Figure 6. Example images of equipment. (A) Standard box and radio frequency identification tag, and (B) personal digital assistant.

The smart scale is the core of the ISBS and its integral parts are presented in Table 6 and Figure 6. 
Table 6. Functions of a smart scale.

\begin{tabular}{|c|c|}
\hline Function & Description \\
\hline Weighing & $\begin{array}{l}\text { Measures the weight of waste, and then transfers weight information to the } \\
\text { logic control section }\end{array}$ \\
\hline Logic Control & $\begin{array}{l}\text { Performs subsequent functions according to the "setting" function based on } \\
\text { data to be transmitted to other components }\end{array}$ \\
\hline Data Transmission & 3G/4G module, sending/receiving information \\
\hline Battery (Optional) & Independent power supply to the device when external power is not connected \\
\hline Other Attachments & $\begin{array}{l}\text { Voice playback components to generate prompt information such as "scale } \\
\text { ready to weigh," "weighing completed, please remove item". Light emitting } \\
\text { diode lamp components to provide network failure tips and other information }\end{array}$ \\
\hline
\end{tabular}

During HW generation, discharged HW is loaded into the standard box, which is subsequently weighed by the smart scale. The smart scale reads the standard box information (standard box unique ID, weight of the HW, and smart scale ID) via the RFID tag and transmits it to the server. Concurrently, the user/operator uses the personal digital assistant to scan the smart scale to obtain the smart scale unique ID and enter relevant HW information. The HW information provided by the user is transmitted to the server where information provided by the smart scale and by users is combined to create complete standard box information.

After the HW is placed into the standard box, it cannot be opened until the final HW treatment. During transportation, all operations can be performed by scanning the RFID without interfering with the HW inside the box. The standard box information will not be reset until the HW has been finally treated at the treatment facility.

\subsubsection{System Optimization Scenarios}

Although HW management in Jiangsu Province has made progress, there remains room for further improvement. The functional map at the government management terminal comprises enterprise management, user management, declaration management, transfer management, disposal management, sub-management, supervision and publicity, notice announcements, and other sections (Figure 3). In this study, certain sections were selected and recommendations were provided for their optimization.

First, the "early warning" function is currently based only on interprovincial HW transfer and secondary HW provided by the HW treatment entities. Warnings are issued when the electronic log looks unusual. To optimize this function, early warning information based not only on the declared amounts but also the positioning and search system and video surveillance should be acquired. Scenarios benefitting from early warning include deviations from the expected exercise routine of HW transport vehicles, such as unexpected opening and closing of vehicle doors.

Secondly, the "supply and demand information platform" for HW disposal from the supervision and publicity module includes two components; that is, information regarding disposal capacity of entities with HW treatment facilities and information regarding HW treatment demand of entities that discharge HW. To optimize this information platform, entities with internal HW disposal facilities should be encouraged to release information when spare disposal capacity is available. Additionally, the platform should indicate supply and demand information based not only on HW quantities but also on HW treatment methods and technologies. Therefore, entities seeking HW treatment are encouraged to publish technique demands for certain HW types such as waste salt. Technical guidance can be provided by specialists from similar entities and social research institutions to ensure efficient recycling of waste resources and effective use of facilities

Thirdly, the authors suggest strengthening the concept of the "chemical/industrial park" in the HWDMSJP. The core of the HWDMSJP is a group of HW-related entities (with regard to discharge, 
treatment, and transportation) classified by administrative regions. However, little emphasis has been placed on the chemical park level. It is suggested that a chemical/industrial park section is installed as part of the HWDMSJP where general and detailed information regarding HW management within a particular park can be clearly demonstrated. This recommendation is particularly significant under the integrated HWM principle as the park is considered as a large entrepreneur and substantial cyclic utilization of $\mathrm{HW}$ is conducted within the park.

In addition, some chemical parks in Jiangsu have already built or are in the process of building HW management systems. In these cases, data docking between the HWDMSJP and HWM platforms of the park (if existing) is highly recommended.

\section{Results and Discussion}

The principles and potential approaches put forward in Section 3 have been reviewed and compared with similar experience from other regions. Three main parts are discussed in detail in this section. The whole structure of this proposal can be seen in Figure 7.

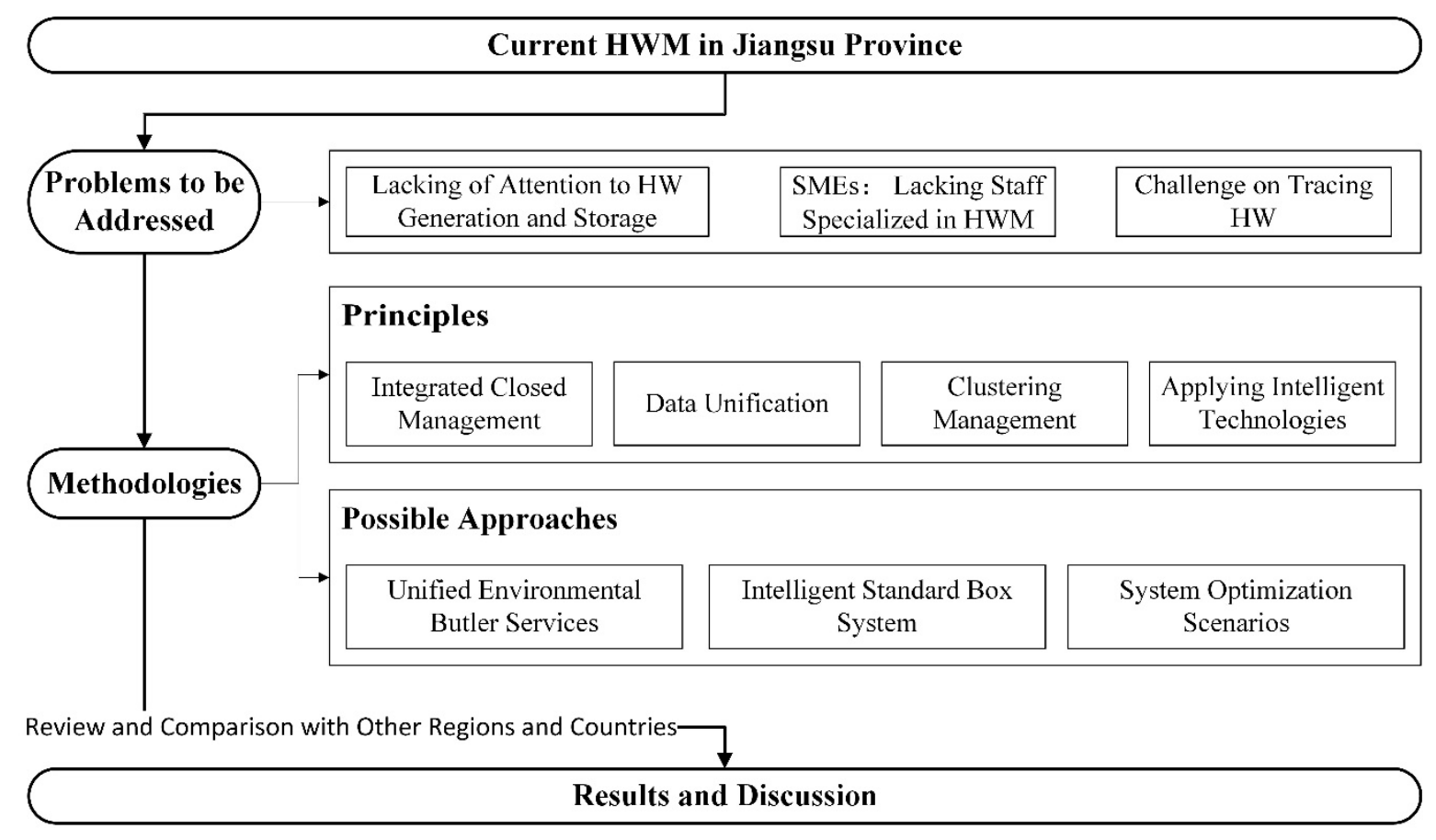

Figure 7. Whole structure of the proposal for HWM.

\subsection{Clustering Management}

With regard to centralized collection and storage for SMEs, the authors found that, the execution of these measures is challenging because of existing laws and regulations at national and regional levels. For example, it is prohibited to collect, store, utilize, or treat HW without a business license [1]. In Jiangsu Province, the costs of applying for an HW business license is relatively high, the procedures are complex, and the cycle is lengthy, all of which impede the implementation of cyclic utilization of HW between entities inside the park. Therefore, governments and local environmental protection departments should take actions to streamline the application process for acquiring business licenses to promote cyclic utilization of HW resources.

With regard to cyclic utilization of HW inside chemical parks, similar principles especially in the topic of cyclic utilization has been recommended by other researchers. Guo et al. proposed promoting industrial symbiosis in chemical industrial parks [23] and Tian et al. researched approaches to improve sulfur utilization efficiency in chemical parks [24]. As one of the most developed provinces in China, Jiangsu Province has been actively exploring green planning, regulations and policies. For example, 
earlier in 2013, it issued documents to promote circular economy development in industrial parks with the aim to facilitate efficient utilization of resources and centralized treatment of emissions [25]. The proposal of implementation of cyclic utilization of HW in the chemical parks would be accepted by local government, hopefully.

\subsection{Application of Intelligent Technologies}

Application of intelligent technologies has been suggested and applied in waste management. Gutierrez et al. presented a waste collection solution based on intelligent trash cans, which used IoT prototypes embedded with sensors to read, collect, and transmit trash volume data over the Internet [26].Vitorino et al. provided a detailed review of technologies and decision support systems to aid solid-waste management and concluded that business intelligence tools and techniques (e.g., data mining, multidimensional analysis) could be utilized for raw data transformation into meaningful and useful information that could potentially benefit decision-making concerning waste management [27]. However, potential challenges exist in practice mainly due to the cost.

Implementation of intelligent application related facilities that utilize monitors and sensors is usually high investment cost and could financially burden the entities. As indicated by Vitorina et al. several technologies are either high cost or in development. These include the IoT (utilizing RFID, sensors, and micro-controllers), trucks equipped with on-board computers and GPS, and GIS software and image processing technologies [27]. Public-private partnership (PPP) is suggested in this regard. The PPP is a framework under which public and private industries assist each other, make joint efforts, and receive mutual benefits while solving social concerns. Service contract, management contract, and rental systems are possible forms of PPP. The areas' richness and variety, demographic and socioeconomic characteristics all have influence on the efficiency of applying intelligent application to HWM.

Jiangsu is a typical province with unbalanced economic development. Total contribution of the three regions to the economic growth of Jiangsu in 2007-2014 varied from 57.63\% (Sounthern Jiangsu) to 18.43 (Central Jiangsu) [28]. As indicated in Figure 1 and Table 2, 53 chemical parks in Jiangsu Province are evenly distributed in three regions. Thus, when introducing intelligent application in to chemical parks in Jiangsu Province, details of intelligent standard box system (ISBS) and system optimization scenarios should vary according to the local economical level.

\subsection{Unified Environmental Butler (EB) Service}

Hebei, Shandong, Dalian and a few other places in China have already introduced the EB service to varying degrees. In early 2018, an EB service project had officially entered an industrial park in Suzhou, Jiangsu. However, the focus has been on general environmental services and HW management is not a priority. As mentioned in Section 3.1.2, a few companies have included HW information in enterprise resource planning for better management of HW within the enterprise. However, as described in Section 2.2, there are enterprises, especially SMEs in the park that still lack sufficient ability and knowledge for HW management.

Though the EB service has many advantages (Section 3.2.1), a few barriers regarding the assignment of responsibilities to the EB exist. Responsibility should undoubtedly lie on the entities discharging HW. The EB should only guide the entities with regard to efficient HWM instead of conducting HWM on their behalf. To conclude, EB services in chemical parks are still in their infancy and barriers in developing a mature working mode, standardized admission for market participants, and clear assignment of responsibilities require further research. Efficient and functional relationship among chemical park committees, entities in the park, and EB service providers take time to develop.

\section{Conclusions}

In this study, principles and possible approaches for the proposal of integrated management of HW at the chemical park level are introduced. Principles such as integrated closed management, data 
unification, clustering management, and application of intelligent technologies were suggested. Based on the case studies of waste management both domestic and abroad, some potential approaches are suggested, including a unified EB service, the ISBS, and optimization of the HWDMSJP. These ideas have been reviewed and compared with similar experience from other regions. However, challenges regarding the financial burden caused by the IoT and intelligent applications, limitations in the practical execution of this approach, and barriers in the assignment of responsibilities to the EB service need to be overcome.

To put this proposal into practice, requires further development. Firstly, the financial cost of all possible hardware devices and equipment must be considered; secondly, experts and professionals in the field of HWM are urgently needed; thirdly, the cooperation willingness between entities and the local environmental protection administrative department also plays an important role.

In the next step, the authors are planning to choose three chemical parks as pilot chemical parks to apply the above principles and approaches, with the help and support from local government and environmental protection departments. The three pilot chemical parks should be each located in SouthJiangsu, Central-Jiangsu, and North- Jiangsu, where the levels of economic development and HW management differ. The aim is to find an approach which suits the local circumstance and apply the integrated management proposal to all the other chemical parks.

Author Contributions: Conceptualization, W.W. and J.B.; methodology, S.Y.; writing-original draft preparation, S.Y.; writing—review and editing, W.W. and J.B.; supervision, G.L. and H.Z.

Funding: This work was supported by the Research Fund of National Key Research and Development Program of China [2018YFC1801606] and Jiangsu Province Key Laboratory of Environmental Engineering [Grant number ZX2017014].

Acknowledgments: We acknowledge the financial support received from National Key Research and Development Program of China and Jiangsu Province Key Laboratory of Environmental Engineering for this study.

Conflicts of Interest: The authors declare no conflict of interest.

\section{References}

1. Standing Committee of the National People's Congress. Law of the People's Republic of China on the Prevention and Control of Environment Pollution Caused by Solid Wastes. 2016 Revision. Available online: http://zfs.mee.gov.cn/fl/200412/t20041229_65299.shtml (accessed on 14 May 2019). (In Chinese)

2. Li, M.; Xu, J.; Li, B. Analysis of Development of Hazardous Waste Disposal Technology in China. IOP Conf. Ser. Earth Environ. Sci. 2018, 178, 12027. [CrossRef]

3. Torretta, V.; Rada, E.C.; Schiavon, M.; Viotti, P. Decision support systems for assessing risks involved in transporting hazardous materials: A review. Saf. Sci. 2017, 92, 1-9. [CrossRef]

4. Fazzo, L.; Minichilli, F.; Santoro, M.; Ceccarini, A.; Della Seta, M.; Bianch, F.; Comba, P.; Martuzzi, M. Hazardous waste and health impact: A systematic review of the scientific literature. Environ. Health A Glob. Access Sci. Source 2017, 16, 107. [CrossRef] [PubMed]

5. Duan, H.; Huang, Q.; Wang, Q.; Zhou, B.; Li, J. Hazardous waste generation and management in China: A review. J. Hazard. Mat. 2008, 158, 221-227. [CrossRef] [PubMed]

6. Ministry of Environmental Protection of the People's Republic of China. Directory of National Hazardous Wastes. 2016 Revision. Available online: http://www.mee.gov.cn/gkml/hbb/bl/201606/t20160621_354852.htm (accessed on 14 May 2019). (In Chinese)

7. Zhang, M.; Wang, Y.; Song, Y.; Zhang, T.; Wang, J. Manifest system for management of non-hazardous industrial solid wastes: Results from a Tianjin industrial park. J. Clean. Prod. 2016, 133, 252-261. [CrossRef]

8. Guiding Opinions on Further Strengthening the Safe Production of Hazardous Chemicals. 2008. Available online: http://www.shsafety.gov.cn/aqzd/cbzhjs/wjhhpqy/xgwjgz/28340.htm (accessed on 14 May 2019). (In Chinese)

9. Bao, J.; Wang, W.; Zhou, H. Planning and Management of Hazardous Wastes in Jiangsu Chemical Industry Park; Hohai University Press: Nanjing, China, 2018. (In Chinese)

10. Arebey, M.; Hannan, M.A.; Basri, H.; Begum, R.A.; Abdullah, H. Integrated technologies for solid waste bin monitoring system. Environ. Monitor. Assess. 2011, 177, 399-408. [CrossRef] [PubMed] 
11. Ministry of Environmental Protection of the People's Republic of China. Annual National Report on Environmental Control of Solid Waste Pollution in Large and Medium Cities. 2018. Available online: http://gts.mee.gov.cn/gtfwgl/gtfwjkglgg/201901/P020190102329655586300.pdf (accessed on 14 May 2019). (In Chinese)

12. Jiangsu Municipal People's Government Notice. 2018. Available online: http://www.jiangsu.gov.cn/module/ download/downfile.jsp?classid=0\&filename=d66fe7408cc54b619208bd82bcfadbae.pdf (accessed on 14 May 2019). (In Chinese)

13. Geng, Y.; Zhu, Q.; Haight, M. Planning for integrated solid waste management at the industrial park level: A case of Tianjin, China. Waste Manag. 2007, 27, 141-150. [CrossRef] [PubMed]

14. Ozaki, H.; Sharma, K.; Phanuwan, C.; Fukushi, K.; Polprasert, C. Management of hazardous waste in Thailand: Present situation and future prospects. J. Mat. Cycle. Waste Manag. 2003, 5, 31-38. [CrossRef]

15. Guiding Opinions of the Ministry of Industry and Information Technology on Promoting the Well-Regulated Development of Chemical Park Zones. 2015. Available online: http://www.miit.gov.cn/newweb/n1146295/ n1652858/n1652930/n4509650/c4533643/content.html (accessed on 14 May 2019). (In Chinese)

16. Ling, J.; Wang, B.; Wen, X. Thinking on promoting the innovation of solid Waste Management by Big Data. Chin. J. Environ. Manag. 2016, 29-32. [CrossRef]

17. Wang, H.; Zhang, T.; Quan, Y.; Dong, R. Research on the framework of the Environmental Internet of Things. Int. J. Sustain. Dev. World Ecol. 2013, 20, 199-204. [CrossRef]

18. Bin, S.; Zhiquan, Y.; Jonathan, L.S.C.; Jiewei, D.K.; Kurle, D.; Cerdas, F.; Herrmann, C. A Big Data Analytics Approach to Develop Industrial Symbioses in Large Cities. Procedia CIRP 2015, 29, 450-455. [CrossRef]

19. Tian, J.; Han, S.; Chen, Y.; Chen, L. Third party environmental governance of chemical industrial pollution. Chem. Eng. Trans. 2017, 62, 613-618. [CrossRef]

20. Lu, H.; Fan, B.; Yuan, L.; Li, Y. RFID-Based Hazardous Waste Management Platform Establishment. Procedia Eng. 2012, 29, 4-8. [CrossRef]

21. Ghose, M.K.; Dikshit, A.K.; Sharma, S.K. A GIS based transportation model for solid waste disposal-a case study on Asansol municipality. Waste Manag. 2006, 26, 1287-1293. [CrossRef] [PubMed]

22. Hannan, M.A.; Abdulla Al Mamun, M.; Hussain, A.; Basri, H.; Begum, R.A. A review on technologies and their usage in solid waste monitoring and management systems: Issues and challenges. Waste Manag. (NY) 2015, 43, 509-523. [CrossRef] [PubMed]

23. Guo, B.; Geng, Y.; Sterr, T.; Dong, L.; Liu, Y. Evaluation of promoting industrial symbiosis in a chemical industrial park: A case of Midong. J. Clean. Prod. 2016, 135, 995-1008. [CrossRef]

24. Tian, J.; Shi, H.; Chen, Y.; Chen, L. Assessment of industrial metabolisms of sulfur in a Chinese fine chemical industrial park. J. Clean. Prod. 2012, 32, 262-272. [CrossRef]

25. PAGE. Transition to a Green Economy in China's Jiangsu Province: A Stocktaking Report. 2016. Available online: http://www.un-page.org/files/public/page_china_stocktakingreport_2016.pdf (accessed on 14 May 2019).

26. Gutierrez, J.M.; Jensen, M.; Henius, M.; Riaz, T. Smart Waste Collection System Based on Location Intelligence. Procedia Comput. Sci. 2015, 61, 120-127. [CrossRef]

27. Vitorino de Souza Melaré, A.; Montenegro González, S.; Faceli, K.; Casadei, V. Technologies and decision support systems to aid solid-waste management: A systematic review. Waste Manag. (NY) 2017, 59, 567-584. [CrossRef] [PubMed]

28. Liu, B.; Xu, M.; Wang, J.; Zhao, L.; Xie, S. Spatio-temporal evolution of regional inequality and contribution decomposition of economic growth: A case study of Jiangsu Province, China. Pap. Reg. Sci. 2018, 1-14. [CrossRef]

(C) 2019 by the authors. Licensee MDPI, Basel, Switzerland. This article is an open access article distributed under the terms and conditions of the Creative Commons Attribution (CC BY) license (http://creativecommons.org/licenses/by/4.0/). 